\title{
LAMINAR FLOW CONTROL LEADING EDGE SYSTEMS IN SIMULATED AIRLINE SERVICE
}

R. D. Wagner, * D. V. Maddalon, * and D. F. Fisher**

\author{
Presented at the 16 th Congress of the International \\ Council of the Aeronautical Sciences \\ Jerusalem, Israel \\ August 28-September 2, 1988
}

*NASA Langley Research Center, Hampton, USA.

**NASA Ames-Dryden Flight Research Facility, Edwards, CA, USA. 


\author{
R. D. Wagner,* D. V. Maddalon,* and D. F. Fisher** \\ Presented at the 16th Congress of the International \\ Counc1l of the Aeronautical Sciences \\ Jerusalem, Israe1 \\ August 28-September 2, 1988
}

\begin{abstract}
Achleving laminar flow on the wings of a conmercial transport involves difficult problems assoctated with the wing leading edge. The NASA Leading Edge Flight Test Program has made major progress toward the solution of these problems. The effectiveness and practicality of candidate laminar flow leading edge systems were proven under representative alrline service conditions. This was accomplished in a series of simulated alrline service flights by modfying a Jetstar aircraft with laminar flow leading edge systems and operating it out of three commercial airports in the United States. The aircraft was operated as an airliner would under actual air traffic conditions, in bad weather, and in insect infested environments.

Two leading edge systems were flown. One used a perforated titanium suction surface with approximately I million, 0.0025 inch diameter, electron beam drilled holes to maintain laminar flow on the wing upper surface to the front spar. This leading edge also had a Krueger-type flap which served as a protective shield against insect impacts. The second leading edge had suction through a slotted titanium skin with 27 spanwise slots (about 0.004 inch wide) on the upper and lower surface; fluid dispensed through some of these slots near the attachment line provided wing surface wetting during takeof to protect against Insect impacts. Both leading edges were equipped with de-icing and fluid purge systems.
\end{abstract}

\section{Introduction}

Previous laminar flow control flight tests, such as the $X-21$, removed any doubt that extensive laminar flow could be achieved in flight (refs.) \& 2). These flight tests did not, however, resolve concerns relative to the practicality of producing surfaces sufficlently smooth and wavefree, and of maintaining the required surface quality during normal service operations. In the late 1970 's, with the recent progress made in the development of new materials, fabrication techniques, analysis methods, and design concepts, a reexamination of these issues appeared warranted.

The leading edge region of a laminar flow wing presents difficult problems associated with the attainment of laminar flow. The leading edge ts subject to forelgn object damage, insect impingement, rain erosion, icing, and other contaminants. In addition, anti-icing, anticontamination, suction and perhaps purge systems

*NASA Langley Research Center, Hampton, VA, USA. **NASA Ames-Dryden Flight Research Facility, Edwards, CA, USA. must all be packaged Into a relatively small leading edge box volume. Most of these problems are common to all the concepts under consideration for the achievement of extensive laminar flow on alrcraft wings; solutions are needed to establish the practicality of this technology for various types of aircraft.

In 1980, NASA initlated the Leading edge Flight Test (LEFT) Program as a flight validation of the LFC leading edge systems, then under development in a cooperatlve program with U.S. alrframe manufacturers. The program objectives were to: (1) demonstrate that the required leading edge systems could be packaged into a wing representative of a subsonic commerclal transport, and (2) demonstrate the performance of these systems in representative operational conditions. The wings of a Lockheed JetStar alrcraft were modifled. Two complete LFC leading edge systems were installed in the left and right wings and flight tests were performed to gain operational experience to assess the practicality of each (see figure 1). The LEFT program thus resulted in the first laminar flow flight test with suction control since the $X-21$ program ended in 1965. References 3 through 11 provide a detailed description of the flight program. Herein, we will provide a program overview. Design, fabrication, and flight experiences will be discussed to provide, in general, an appraisal of the systems tested including the performance in the actual airline environment.

\section{Aerodynamic Design}

The aerodynamic design of the modified JetStar wing was subject to several constraints. The test articles were designed to be installed in the leading edge opening created by removal of auxiliary fuel tanks on the basic wing. The planform of the modifled wing is shown in figure?. The modification spanned about 7 feet of the wing with the suction articles about 5 feet in span. The sweep of the basic wing limited the sweep of the test articles. Outboard and inboard, the sweep of the basic Jetstar wing is 33 degrees; the test articles were swept 30 degrees. To produce the destred pressure distribution, the wing section required extensive modification in the test area. The contour of the wing to the rear spar on the upper surface and to the front spar on the lower surface was changed with installation of the test articles and fiberglass fairings over the wing box and at the extremities of the test article. The gloved wing was significantly thicker than the basic Jetstar as the inserts in figure 2 indicate, particularly in the outboard region of the glove. A fortultous result of the thicker wings was that the test articles were dimensionally about equivalent to the leading edge box of a DC-9-30 at the mean aerodynamic chord. Thus, the 
volume of the leading edge available for systems installation was representative of a small commerclal transport.

The design pressure distribution is shown in figure 3. The design goal was a pressure distribution in the test region that would be characteristic of a future LFC transport, a roof-top pressure distribution with supercritical flow over the wing box. The flight data in figure 3 confirmed that this was achieved over the possible range of cruise conditions expected to be encountered by the JetStar.

A typical suction distribution for the upper right wing is shown in figure 4. The lower surface suction distributions on the left wing were similar. The suction levels were selected to be representative of the suction that would be required in the leading edge box on an LFC wing with near full chord laminar flow; that is more suction than would be required to get laninar flow to just the front spar. This was done so that the suction ducting volume requirement would be representative of future application requirements. High initial suction levels were required to control cross flow in the leading edge. Beyond $x / c$ greater than 0.05 , a lower level of $\mathrm{Cq}$ was maintained to the front spar, again to be representative of the suction distribution that would be required in an actual application with laminar flow expected beyond the front spar. Stability calculations were made to determine the adequacy of suction levels and sample results are shown in figure 4 . The growth of both crossflow vortices and TollmienSchlichting waves were calculated; the latter were found to be stable ahead of the front spar. Cross flow $\mathrm{N}$ factors in figure 4 show that suction was needed to achieve laminar flow ahead of the front spar. Indeed, flight tests with suction blocked of $f$ by sealing the perforations with wax showed transition to occur from 2 to 6 percent chord downstream of the attachment line, depending upon flight conditions; for the condition calculated in figure 4, the average transition location was about 2 percent chord. With design suction levels (ref. 5), the cross flow $\mathrm{N}$ factors were lowered to values consistent with the achlevement of laminar flow in the leading edge.

\section{Leading Edge Systems Design}

Detailed descriptions of the leading edge systems flown on the Jetstar are provided in references 4 and 5. Each system was complete in that it included all the subsystems necessary to provide all the functions required for an LFC aircraft; although different subsystems were used in each. The system on the right wing was installed in a structure consisting of a sandwich panel supported by ribs attached to the front spar (see figure 5). The outer face sheet of the panel was the suction surface, a titanium sheet, 0.025 inch thick, perforated with over 1 million holes, 0.0025 inch in diameter, drilled by an electron beam with 0.035 inch spacing between centers. The core of the panel and the Inner face sheet were constructed of fiberglass. The core was corrugated to form flutes for subsurface suction afr collection. The bond areas between the perforated surface and the core were impervious to flow; thus, suction on the surface was along spanwise perforated strips spaced about 0.65 inches apart. Suction was applled to just the upper surface back to the front spar. No attempt was made, with either leading edge, to achieve laminar flow beyond the front spar. The perforated leading edge housed a Krueger-type edge device that deployed to provide 1ine-of-sight protection to the main wing against insect impacts during takeoff and landing. The Krueger had a glycol fluid de-lcing system, a commerclally available system which dispensed a freezing point depressant fluid through a porous strip along the Krueger leading edge. On the downstream side of the Krueger was a spanwise row of spray nozzles which dispensed a $60 / 40$ mixture of Propylene Glycol Methyl Ether (PGME), a freezing point depressant, and water. These nozzles provided icing protection for the main wing and also could be used to wet the wing on takeoff or landing to supplement the insect protection of the Krueger. A system was also provided to purge the wing ducts and perforated surface of any fluids that might be ingested. This was simply a pressurized air source with ducting to produce a positive pressure differential (about $1 / 2 \mathrm{psl}$ ) across the suction surface.

The leading edge system with the perforated suction surface presented no difficult fabrication problems. Indeed, a major outcome of the LEFT program is considered to be the emergence of the electron beam perforated titanium as suction surface matertal that can be worked with practical fabrication methods to meet the stringent laminar flow surface quality requirements.

Figure 6 shows the perforated test article installed on the Jetstar. The white areas inboard and outboard of the test article are the aerodynamic fairings which falr the test article contour back into the the JetStar wing surface. Aft of the front spar, a fairing also extends to the rear spar to close out the wing sections. The step in the outboard fairing is indicative of how much thicker the new wing sections are relative to the basic Jetstar wing sections. A row of surface pitot tubes can also be seen at the front spar, as well as two pitot tubes used to measure a reference pressure in the airstream over the wing outside the boundary layer. A closeup of these tubes is shown in figure 7; the surface pitots were used to determine if laminar flow existed at the front spar, and to locate the approximate transition location ahead of each tube. They were flight callbrated for transition location by placing transition strips at known locations on the test surface.

The leading edge system with the slotted suction surface is lllustrated in figure 8 . The leading edge box structure is a sandwich construction. A 0.016 inch thick titanium outer sheet is bonded to a sandwich of graphite-epoxy face sheets with a Nomex honeycomb core. Suction is accomplished through fine, spanwise slots $(0.004$ inch wide) on both the upper and lower surfaces to the front spar. The suction al $r$ is routed through the structure by a combination of slot ducts, metering holes, and collector ducts embedded in the honeycomb. The insect protection system is integrated with the anti-icing protection system. A $60 / 40$ mixture of PGME and water is dispensed through slots above and below the attachment line. The fluid wets the surface to provide anti-icing or 
Insect protection; previous flight and wind tunnel tests have shown that insects do not adhere to a wet surface. These slots are purged of fluid after climb out and through a system of check valves, suction is applied to these slots at crulse. The purge pressure can also be applied to the remaining slots.

Fabrication of the slotted leading edge presented formidable problems. Spring back of the initlally roll formed outer titanium sheet was experfenced when the slots were cut. To circumvent this problem the skin was hot formed to stress relieve the skin in the desired contour. Bonding the skin to the substructure then became a problem because of the prectsion needed to minimize bond lines and adhesive flow into metering holes and ducts. Alignment of slot ducts with slots was also difficult because of the small duct dimenstons and precision required. Two articles were bullt to flight standards. The first was considered to be flawed and was used for structural integrity tests. In spite of the lessons learned on the first article, the second article also experienced flaws that required extensive repair and then only marginally met laminar flow surface quality criterla. Funding constraints prevented further attempts to improve the article. A photograph of this flight article installed on the left wing is shown in figure 9.

\section{Aircraft Modifications}

A schematic of the JetStar modified for the LEFT program is presented in figure 10. The heart of the suction system is a centrifugal air turbine compressor used as a suction pump, a modified AiResearch turbocompressor originally designed for the air-conditioning system on the Boeing 707 . The compressor is located in the unpressurized rear fuselage compartment. To permit optimization of the systems, each of the 15 suction flutes on the perforated test article and each of the 27 slots on the other test article have Individual flow control. This is accomplished through the use of chamber valves in the fuselage cabin. One chamber valve controls air flow in the 15 ines from the perforated article, and there are separate chamber valves for the upper and lower surface suction 1 ines of the slotted test article. Each suction line feeds into a sonic needle valve In the chamber valve. These valves are adjustable in the cabin for flow control. The valve control and data acquistion is accomplished at two operator stations in the cabin (see figure 10). The sonic valves were calibrated for mass flow measurements. These measurements, as well as measurements of the surface pressures, duct pressures, surface and reference pitot pressures, and other system and flight parameters could be read on two CRT displays in the cabin at the control consoles.

Figure 11 shows the modified alrcraft in flight. The pylon on the fuselage was used as a mounting for a Knollenberg probe to measure ice particle size and count during tce cloud penetrations. It also housed a charge patch for measurement of alrcraft charge bulld up during cloud encounters (refs. 8 and 9 ).

\section{Initial F1ight Results}

Extensive flight testing was first performed at the NASA Ames-Dryden Flight Research Facility to optimize the performance of the systems on the flight articles. The initial flight test results for the perforated test article are shown in $\mathrm{f1g}$ ure 12, which 11lustrates the laminar flow area on the test article as a function of the Mach number at varlous altftudes in clear air. These data are derived from the 20 surface pitot probes at the front spar. Approximate transition locations ahead of each probe were determined and the laminar flow area derived. This figure shows that the test points at the lowest speeds and highest altitudes (i.e., the lowest Reynolds number) resulted in the most laminar flow. Conversely, the data at lowest altitudes and highest speeds (the highest Reynolds number) resulted in the least laminar flow. At the design point, $M=0.75$ and $38,000 \mathrm{ft}$. , approximately 83 percent of the test article was laminar. At the off-design point of Mach $=0.705$ and $38,000 \mathrm{ft} ., 97$ percent of the test article had laminar flow, whereas at $M=0.78$ and $32,000 \mathrm{ft}$, this value was only 7 or 8 percent. This poorer performance at higher Reynolds number was suspected to be caused by spanwise turbulence contamination (ref. 7).

As seen in the right part of figure 13, the transition front on the perforated leading edge moved from inboard to farther outboard as the altitude was reduced and the Reynolds number increased. Approximate values of the attachment IIne momentum thickness Reynolds number, $\operatorname{Re}_{\theta}$, indicate that the critical value, $\operatorname{Re}_{\theta}=100$ (ref. 1), is exceeded over the range of flight conditions and the movement of the transition front is consistent with the increasing values of $\mathrm{Re}_{\theta}$. The inftial findings from the perforated test article are replotted (in figure 13) as a function of the momentum thickness Reynolds number. As $\operatorname{Re}_{\theta}$ is reduced to values near 100 , the extent of laminar flow approached 100 percent. These flights thus clearly indicated a need to provide some protection from turbulence contamination from the inboard part of the wing.

Several approaches to control spanwise turbulence contamination were examined. A Gaster bump (ref. 12) was first attempted, but the best results were obtained with an integral notch-bump in the Inboard leading edge (see flgures 6 and 14). This configuration allowed the achlevement of nearly full laminar flow over the entire perforated test article (to the front spar) at the conditions tested (see figure 15). Some modification of the design suction distribution contributed to this improved performance. The suction was increased in the aft flutes. In general, the areas where laminar flow was lost were belleved due to locally poor isobar patterns or surface imperfections due to instrumentation installations. There was also some evidence of laminar boundary layer separation at higher speeds and altitudes. With the improved configuration, at the design condition, $M=0.75$ and an altitude of $38,000 \mathrm{ft}$, the test artfcle was 96 percent laminar. The areas of laminar flow loss were turbulent wedges near the front spar.

The slotted test article with the notch-bump did not maintain laminar flow as consistently as 
the perforated article (figure 16). Near the design conditions, the test article surface varied between 80 and 94 percent laminar (see figure 16). At other Mach numbers and altitudes, the data were scattered without a clear indication of why the performance was poorer. These effects are probably the result of the poorer surface quality of this article compared to the perforated article. It was felt however, that the performance was repeatable enough so as not to Invalidate the simulated airline service to be performed later in the program.

Flights were also made to optlmize the performance of the fluid wetting systems of both test articles. Actual functional performance for Insect protection or anti-1cing was not evaluated; this was accomplished in the simulated alrline service to be discussed later. Initially, only good wetting of the protected surfaces was a goal. Figures 17 and 18 are inflight photographs of each fluid system in operation. Wetting of both surfaces was good with flow rates of about 1.5 and 1.0 gallons per minute through the slots or spray nozzles, respectively. The operation sequence for the fluid, purge, and suction systems is illustrated in figure 19.

\section{Simulated Airline Service}

To evaluate the effectiveness and practicality of the laminar flow leading edge systems in representative alrline service, a series of simulated airline flights were made. The alrcraft was operated out of three major commerctal afrports (Atlanta-Hartsfield, Greater Pittsburgh International, and Cleveland Hopkins International) to other airports in the United States. The aircraft was operated as an alrliner would under actual air traffic conditions, in bad weather, and exposed to the alrport pollutant and insect environment. The JetStar is shown in figure 20 being serviced during the simulated service from Pittsburgh in September 1985.

During the simulated service, one to four flights per day were made from the home base alrport; a total of 62 flights were made to 33 different airports in the United States (see figure 21). Filghts were made from Atlanta in July 1985, from Pittsburgh in September 1985, and from Cleveland in February 1986. Thus, the weather conditions experienced varied from extreme summer to severe winter conditions.

The simulated service flights were made as similar to commercial transport operations as was possible. This included scheduled take of $f s$ and landings; queuing up with the commercial airliners in the flight line, use of alr traffic control of vector, altitude and speed; and operation at vartous times of day including peak traffic hours. Before, during, and after filghts, the alrcraft was exposed to the airline environment and was parked overnight on the apron. The LFC systems were operated in a hands-off mode; no adjustments were permitted in flight and the same suction control settings were used for all flights, 1.e., the systems were operated in an on/off mode.

\section{Evaluation of LFC Systems}

All five of the laminar flow control systems were evaluated during the simulated service flights. The suction system was operated on all flights and the other systems used as weather or environmental conditions required.

A typical flight profile with laminar flow performance for the perforated article is shown in figure 22. These data are for a flight from Atlanta to Atlantic City on February 20, 1986. The laminar flow achieved was steady over long pertods during the flight through clear air. At three times during the flight, high altitude ice clouds were encountered and loss of laminar flow was experienced. Cloud penetrations were indicated by the charge patch instrumentation on the pylon. The insert in figure 22 shows how the laminar flow was distributed across the span before, during, and after a cloud penetration. Prior to the cloud entry, 100 percent laminar flow was registered on the leading edge to the $f$ ront spar. In the cloud, the transition front was near uniform across the span at about 5 percent chord. Note, however, good performance was restored after passing through the cloud. This was typical of cloud effects on the laminar flow run. With the exception of cloud penetrations, the amount of laminar flow obtained at cruise conditions was basically unchanged from the clear alr performance obtained in flights out of the Ames-Dryden Flight Research Facility. Experience showed that ice cloud encounters at altitude were infrequent; less than 7 percent of the accrued cruise time was in clouds.

Examination of figure 22 also shows that in descent appreciable amounts of laminar flow were obtained at lower than cruise altitudes. In fact, laminar flow was obtalned at altitudes as low as 10,000 feet with no adjustment of the suction flow nozzle settings from cruise settings.

There appeared to be no appreciable degradation of the suction surfaces with service time. In particular, the perforated suction surface showed no tendency to clog; the porosity not changing over the flight test program. Degradation of the slotted surface was more difficult to monitor because of the overall poorer performance due to the surface imperfections previously mentioned. In general, in clear air the simulated service performance matched the earlier experience at Ames-Dryden.

Both systems for insect contamination performed well during the simulated airline service. In the service operations out of At lanta and Pittsburgh, insect contamination was evident on the slotted leading edge upon landing. These Insect deposits were belleved due to impacts during descent. The insect protection system was not used during landing on the slotted test article for the following reasons: (1) the long approaches to landing would require considerable amount of fluids be carried throughout the flight, (2) purging the liquid from the slots and ducts after landing requires high power settings of the engines and the resulting nolse level would be very undesirable, (3) post-flight cleaning could be accomplished simply and most effectively by the ground crew. Visual observations of the leading 
edge during climbout and cruise indicated that the fluid wetting system did keep the slotted leading edge clean for those portions of the flights. Between flights, a damp cloth was used to clean the slotted leading edge. Cleaning of the perforated leading edge between flights was not necessary. The Krueger shield was used on both takeoff and landing and was almost completely effective in eliminating insect deposits.

The severity of the insect contamination problem is illustrated in figure 23. The result of a post flight inspection of the leading edges after a flight from Boston to Pittsburgh in September 1985 is shown. The upper surface of the slotted leading edge revealed a great number of insect deposits, many of sufficient height that they would cause boundary layer transition at cruise conditions. Two insect deposits were observed on the inboard end of the perforated leading edge. The occasional deposits that did occur in this area were a consequence of the shield design which did not provide protection at the inboard edge. It was noticed that this insect debris tended to erode away in subsequent flights, and that passage through cloud cover provides a natural washing of the surfaces. Midway through the Pittsburgh service, it was found that the shield alone was sufficlent to protect the leading edge from insect impacts; use of the supplemental spray was then discontinued.

The system for purging the fluids from the air passages operated satisfactorily in flight and on the ground, in winter or summer operations. During the simulated service in Atlanta, while on the ground, the atrcraft was exposed to a heavy rainfall of over 1.3 inches in a short time. The next morning rain water which had seeped into the ducting was easily purged from the ducts, slots, and perforations. With the purge system, accumulation of ground de-icing fluids in the ducts, etc., also presented no problems.

In flight lcing was encountered in the winter simulated service from Cleveland in February 1986. Although these encounters were quite $11 \mathrm{mited}$, visual observations indicated both anti-icing systems were effective. Subsequent laminar flow monitoring in high altitude crutse indicated no apparent problems with fluid runback and refreezing on the suction surfaces.

Quite severe winter weather was experienced in the Cleveland operations. As the photographs in figures 24 through 26 indicate, severe snow and ice accumulation on the aircraft occurred. With conventional equipment, ground de-icing of the test surfaces was no more difficult than normal de-icing of commercial aircraft. Snow and ice was easily removed with hand-held de-icing equipment (see figure 27). The purge system then removed any fluids in the perforations, slots, or ducts.

In general, the results of the simulated airline service have been very encouraging. Systems have been demonstrated that provide practical solutions to the difficult problems anticipated in the leading edge region of commercial transports. In a cooperative program, NASA, the U.S. Air Force, and the Boeing Company are currently pursuing the next important step towards the introduction of laminar flow technology into new atreraft.

\section{High Reynolds Number HLFC Experiment}

A high Reynolds number hybrid laminar flow control (HLFC) flight experiment will be performed on a Boeing 757 afrcraft equipped with a partial span HLFC system on the upper surface of the left wing (see figure 28). A 20-foot span of the wing just outboard of the left engine pylon will be modifled. A new leading edge box will be installed with suction achieved through a perforated titanium surface. The structural concept will be similar to that used on the JetStar for the Leading Edge Flight Test and will Include a leading edge Krueger fully integrated into the wing highlift system and designed to be an insect shield (figure 29). Laminar flow over the leading edge will be achieved by suction and a favorable pressure gradlent over the wing box will be expected to maintain laminar flow to possibly 60 percent chord at Reynolds numbers exceeding 30 million. Thus, this approach to achieving extensive laminar flow is a hybrid of laminar flow control and natural laminar flow. An extended flight test program is planned for calendar year 1990 to achieve operational experience with the HLFC system.

\section{Concluding Remarks}

Much progress has been made toward developing practical systems for laminar flow control commercial aircraft. The Jetstar flight program demonstrated that the difficult leading edge region problems could be sucessfully overcome. With success in the 757 program, the long awaited transfer of laminar flow technology to the drawing board and ultimately to practice could follow.

\section{References}

1. Pfenninger, W.: Laminar Flow Control Laminarization. Special Course on Concepts for Drag Reduction, AGARD Report No. 654, June 1977.

2. Edwards, B.: Laminar Flow Control - Concepts, Experfences, Speculations. Special Course on Concepts for Drag Reduction, AGARD Report No. 654, June 1977.

3. Wagner, R. D.; Maddalon, D. V.; and Fischer, M. C.: Technology Developments for Laminar Boundary Layer Control on Subsonic Transport Aircraft. AGARD Conference on Improvement of Aerodynamic Performance Through Boundary Layer Control and High Lift Systems. AGARD Report No. 365,1984 .

4. Etchberger, F. R.: Laminar Flow Control Leading Edge Glove Flight - Alrcraft Modification Design, Test Article Development, and Systems Integration. NASA CR-172136, 1983.

5. Douglas Aircraft Company Staff: Laminar Flow Control Leading Edge Flight Test Article Development. NASA CR-172137, 1984. 
6. Fischer, M. C.; Wright, A. S., Jr.; and Wagner, R. D.: A Flight Test of Laminar Flow Control Leading Edge Systems. NASA TM-85712, 1983.

7. Fisher, D. F.; and Fischer, M. C.: The Development Flight Tests of the JetStar LFC Leading Edge Flight Experiment. NASA CP 2487, 1987.

8. Davis, R. E.; and Fischer, M. C.: Cloud Particle Ef fects on Laminar Flow in the NASA LEFT Program: AIAA Paper 86-9811, 1986.

9. Davis, R. E.; Maddalon, D. V.; and Wagner, R. D.: Performance of Laninar Flow Leading Edge Test Articles in Cloud Encounters. NASA CP $2487,1987$.

10. Powell, A. G.; and Varner, L. D.: The Right Wing of the LEFT Airplane. NASA CP 2487 , 1987.

11. Maddalon, D. V.; Fisher, D. F.; Jennett, L. A.; and Fischer, M. C.: Simulated Airline Service Experience with Laminar Flow Control Leading-Edge Systems. NASA CP 2487, 1987.

12. Gaster, M.: A Simple Device for Preventing Turbulent Contamination on Swept Leading Edges. Journal of the Royal Aeronautical Society, Vol. 69, pg. 788, 1965.

Objective:

Demonstrate the effectiveness and practicality of L.E. Systems in maintaining laminar flow under representative transport flight conditions.

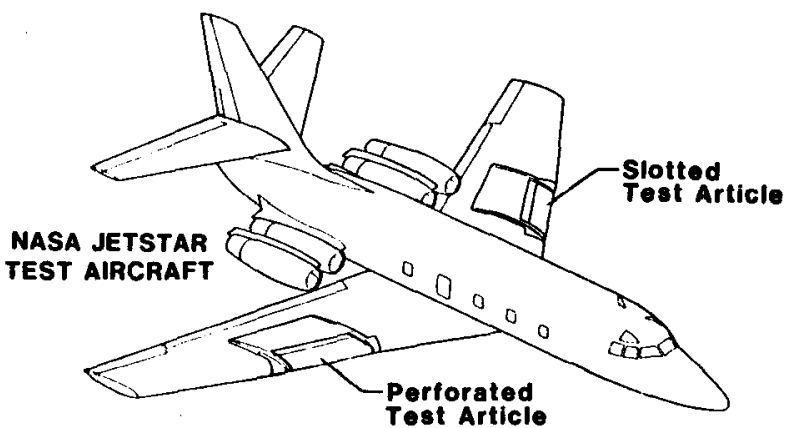

Figure 1 - The NASA Leading-Edge Flight Test JetStar Aircraft

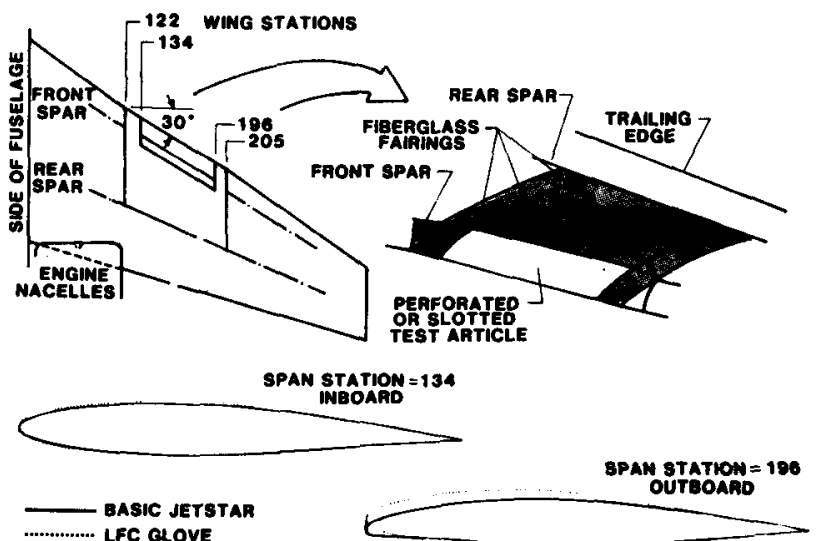

Figure 2 - The LEFT JetStar Planform and Wing Sections

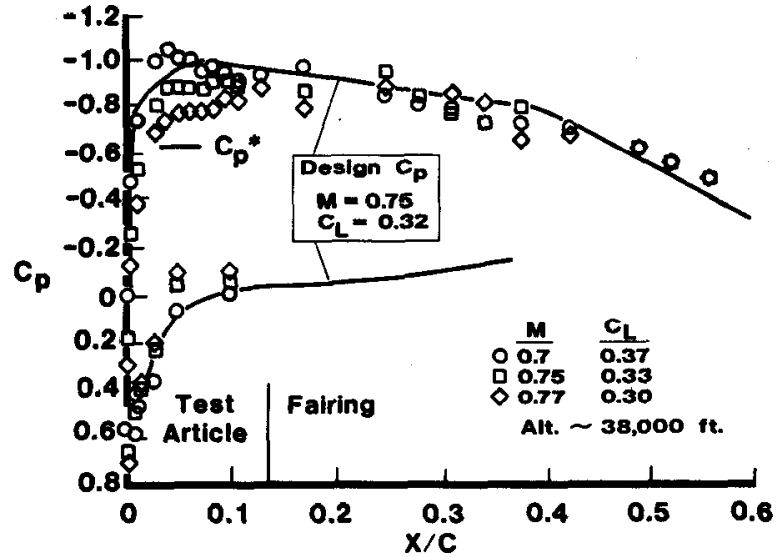

Figure 3 - Design and Flight Pressure Distributions

$M=0.75$

Alt. $=29,000 \mathrm{ft}$

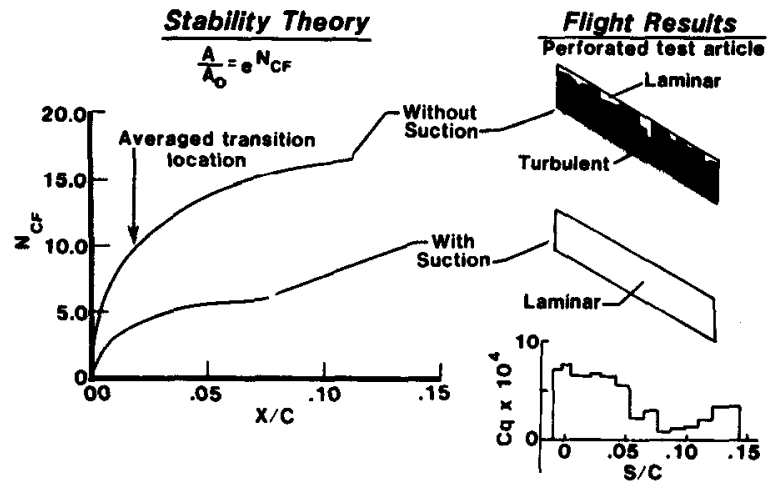

Figure 4 - Effect of Suction on Stability and Transition

- Suction on upper surface only

- Suction through electron-beam perforated skin

- Leading-edge shield extended for insect protection

- De-icer insert on shield for ice protection

- Supplementary spray nozzles for protection from insects and ice

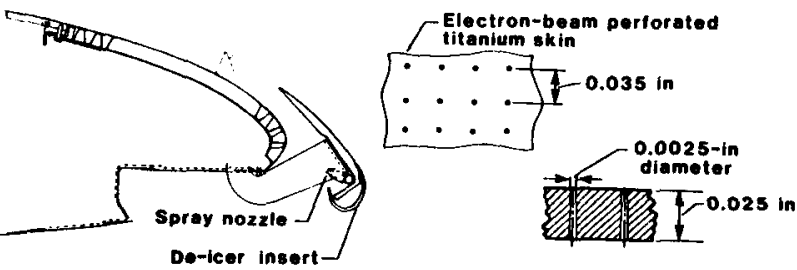

Figure 5 - Cross Section of the Perforated Test Article 


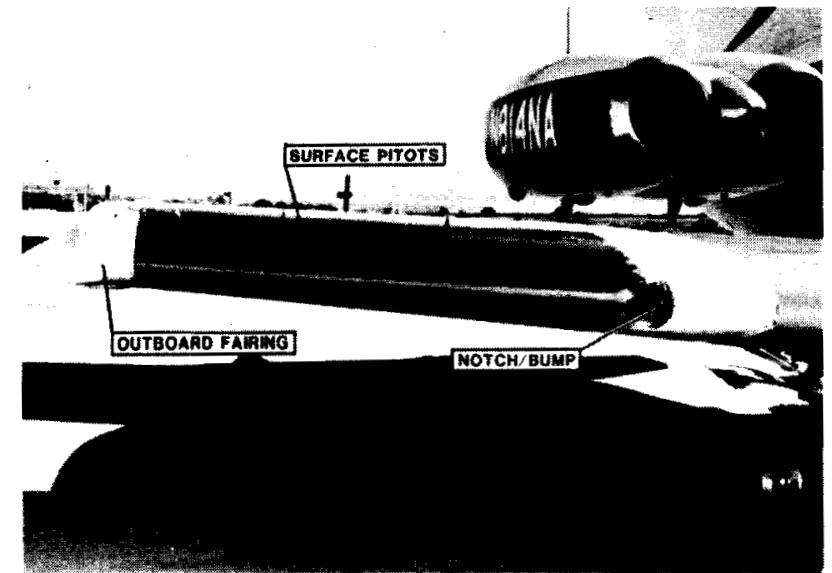

Figure 6 - Perforated Test Article Installed on LEFT Alrcraft

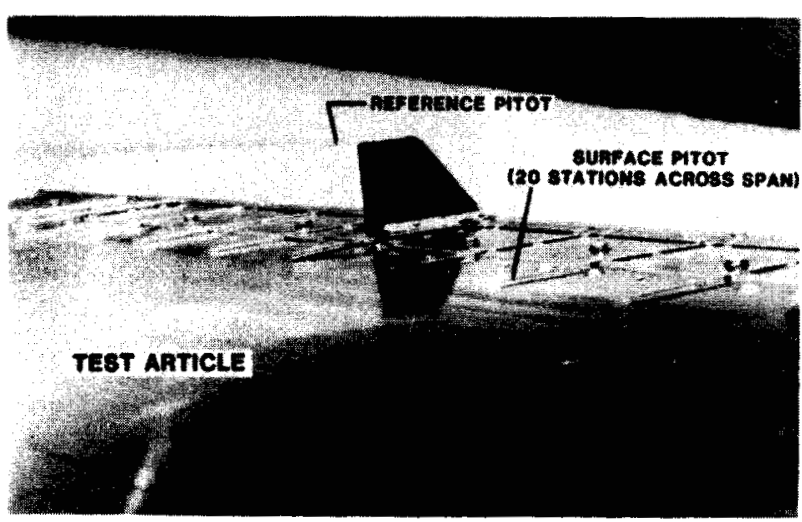

Figure 7 - Transition Instrumentation at Front Spar

- Suction on upper and lower surface

- Suction through spanwise slots

- Liquid expelled through slots for protection from insects and icing

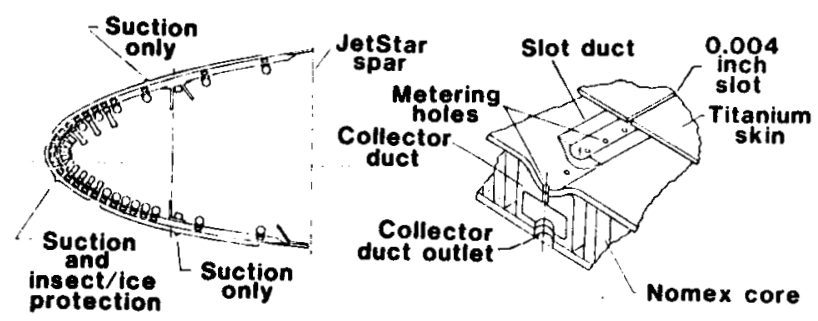

Figure 8 - Cross Section of Slotted Test Article

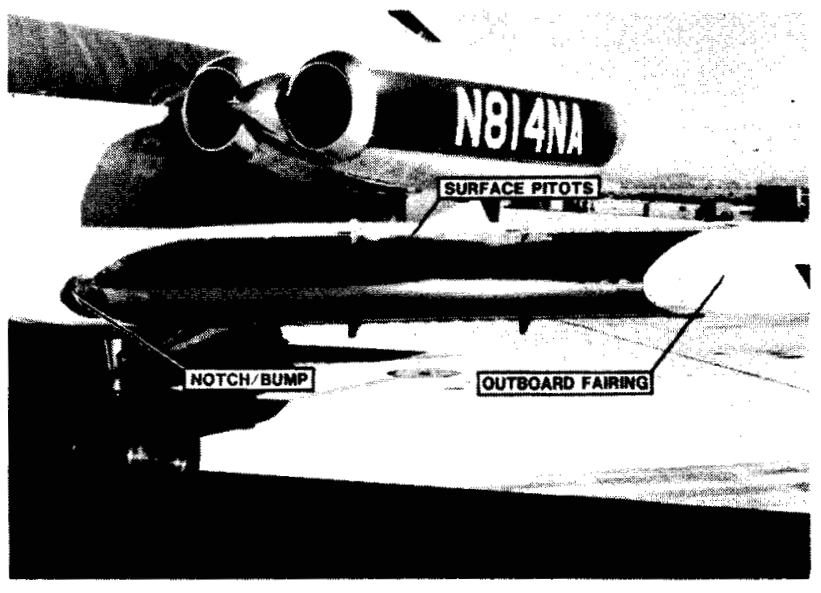

Figure 9 - Slotted Test Article Installed on LEFT Aircraft

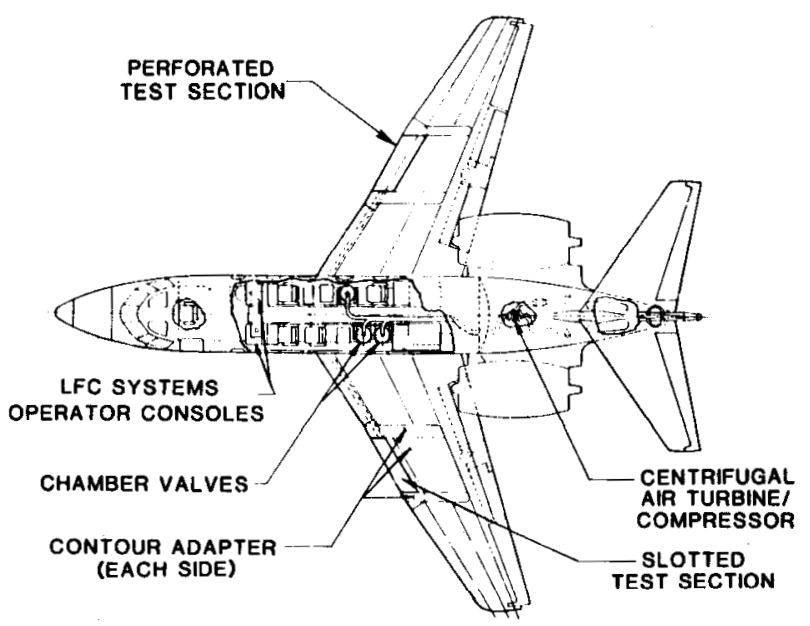

Figure 10 - Modified JetStar Configuration

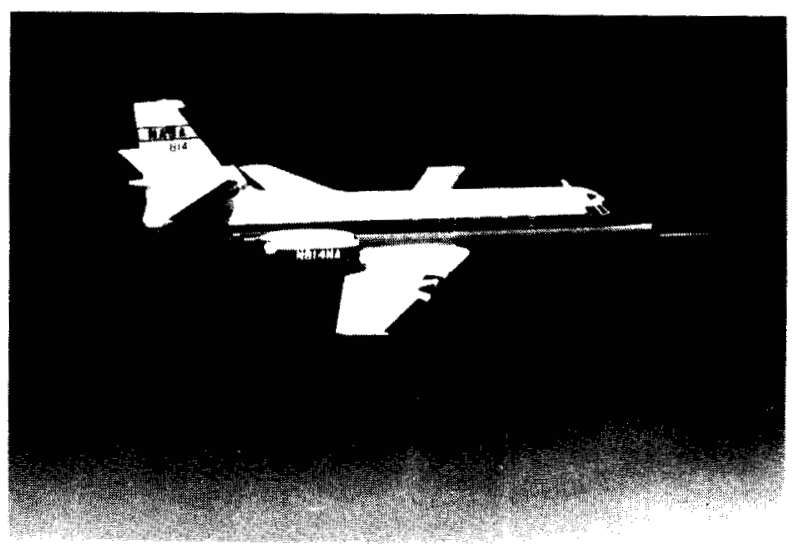

Figure 11 - LEFT JetStar in Flight 
Alt.

- 32,000

$1-.-136,000$

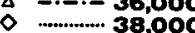
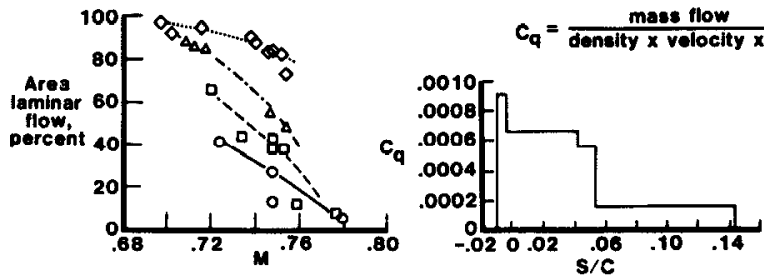

Figure 12 - Percent Areal Laminar Flow - Initial Flights

\section{Perforated Test Article; Initial Findings} Alt, it.

O $32,00000.724$ to 0.780

$36,000 \quad 0.708$ to 0.754

$\begin{array}{lll}38,000 & 0.697 \quad 10 & 0.748\end{array}$

$R_{\theta_{\theta}} \approx \sqrt{\frac{.07 \sin \lambda}{\cos \lambda} \sqrt{R_{\theta_{\infty}}} \text { LE radius }}$
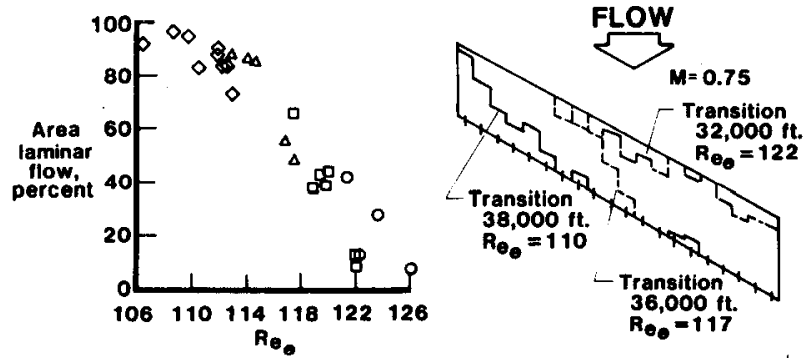

Figure 13 - Percent Laminar Flow Versus Momentum Thickness Reynolds Number

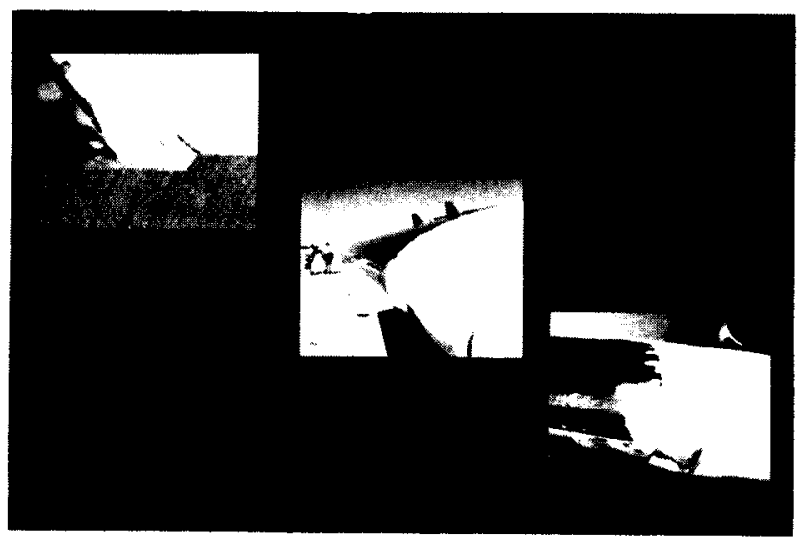

Figure 14 - Notch/Bump Device
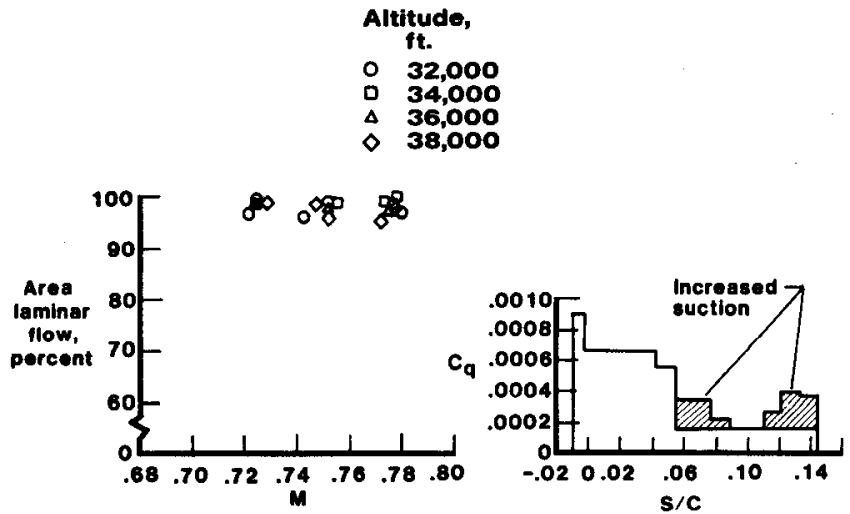

Figure 15 - Perforated Percent Areal Laminar Flow With Notch/Bump

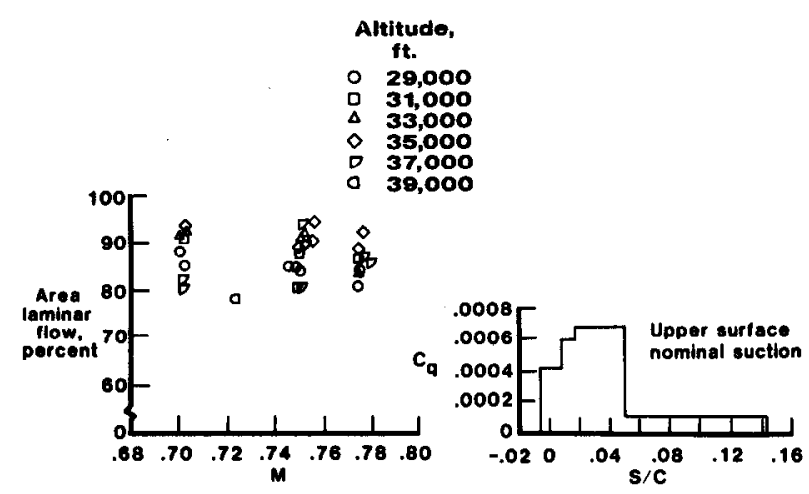

Figure 16 - Slotted Percent/Areal Laminar Flow With Notch/Bump

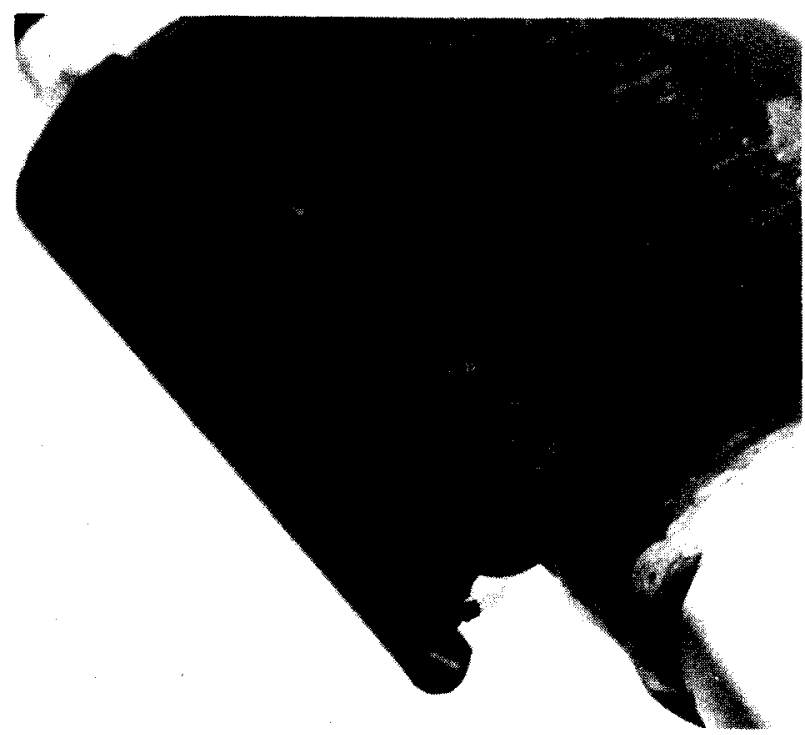

Figure 17 - Perforated Test Article Insect/Ice Protection System in Flight 


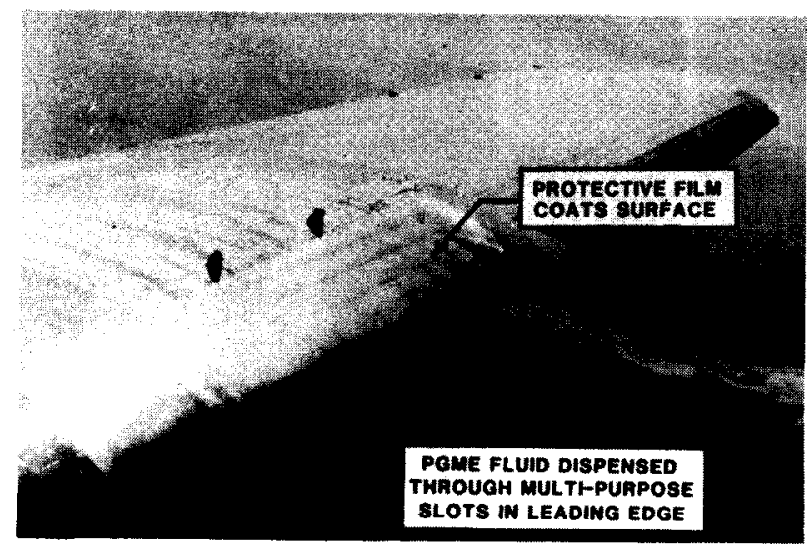

Flgure 18 - Slotted Test Article Insect/Ice Protection System in Flight

\begin{tabular}{|c|c|c|c|}
\hline & $\begin{array}{l}\text { TIVE } \\
\text { ELAPSES waK }\end{array}$ & SLOTREO & PEAFOAATEO \\
\hline Takeoff & o & Liquid on & $\begin{array}{l}\text { Shield extended } \\
\text { Liquid on }\end{array}$ \\
\hline $1,000 \mathrm{ft}$ & 1 & Liquid off & $\begin{array}{l}\text { Liquid off } \\
\text { Purge on }\end{array}$ \\
\hline 4,000 ft. & 2 & & Rotract shield \\
\hline $20,000 \mathrm{ft}$. & 8 & $\begin{array}{l}\text { Suction pump } \\
\text { start }\end{array}$ & $\begin{array}{l}\text { Suction pump } \\
\text { start }\end{array}$ \\
\hline $23,000 \mathrm{ft}$. & 10 & Purge off & Purge off \\
\hline $32,000 \mathrm{ft}$ & 15 & $\begin{array}{l}\text { Beginning of } \\
\text { suction on test } \\
\text { article }\end{array}$ & $\begin{array}{l}\text { Beginning of } \\
\text { suction on test } \\
\text { article }\end{array}$ \\
\hline
\end{tabular}

Figure 19 - LEFT Operations and In-F1ight Leading Edge Washing

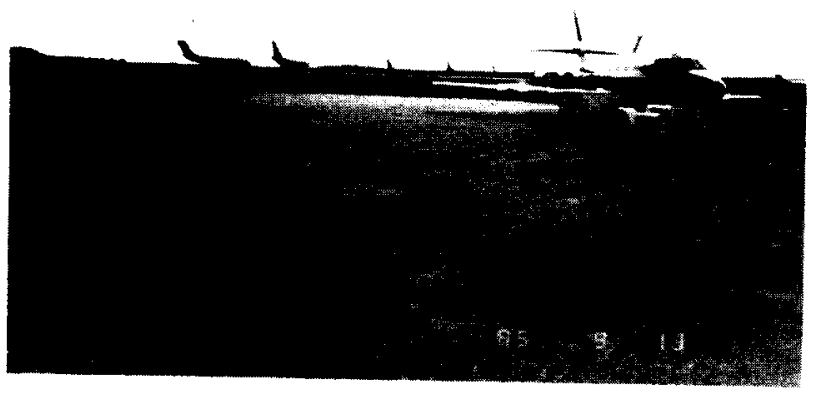

Figure 20 - LEFT JetStar Serviced in Pittsburgh
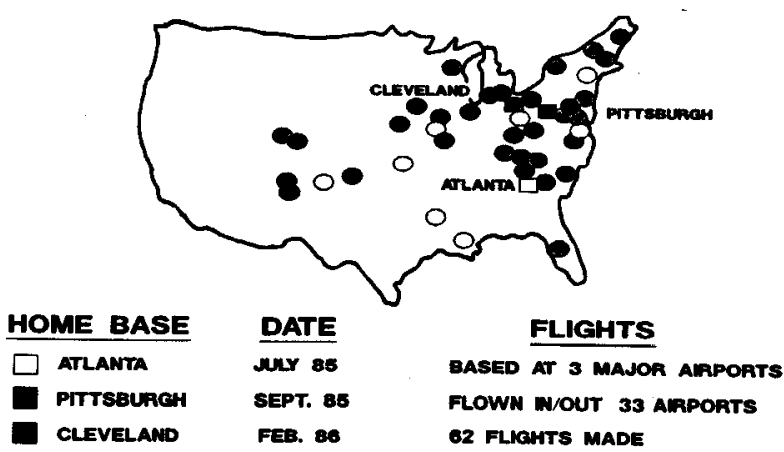

Figure 21 - Simulated Airline Service Flights

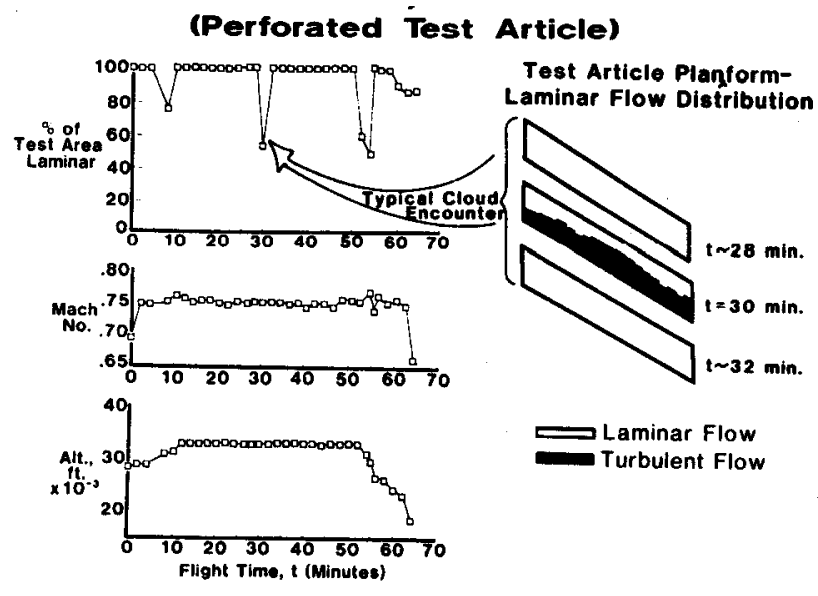

Figure 22 - Typical Flight Profile

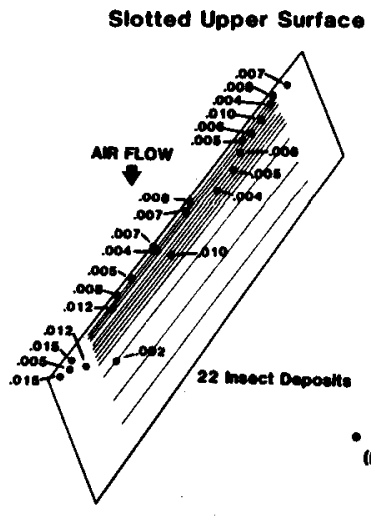

Perforated Upper Surface

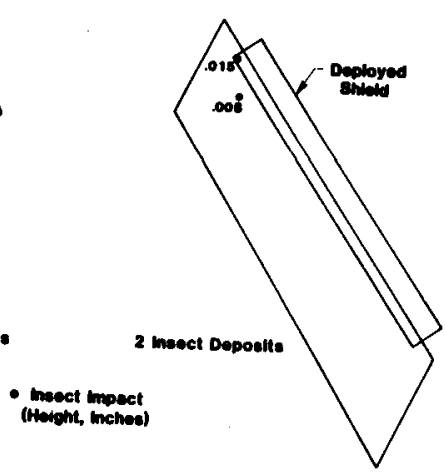

Figure 23 - Typical Insect Contamination 


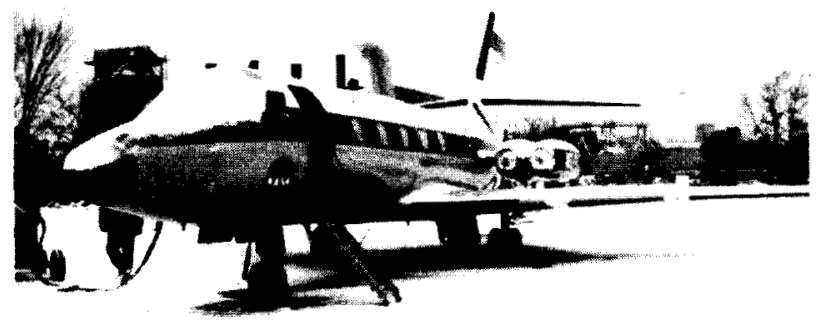

Figure 24 - LEFT JetStar During Cleveland Service
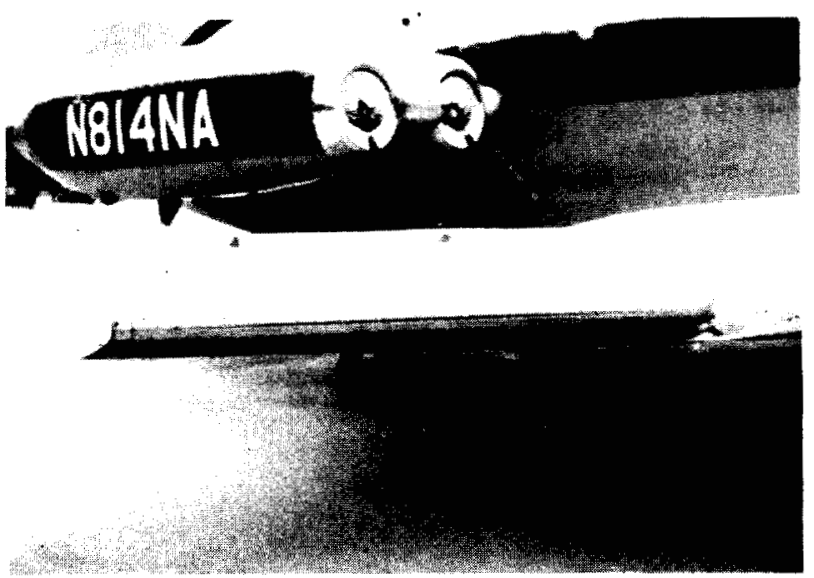

Figure 25 - Snow Deposits on Right Wing

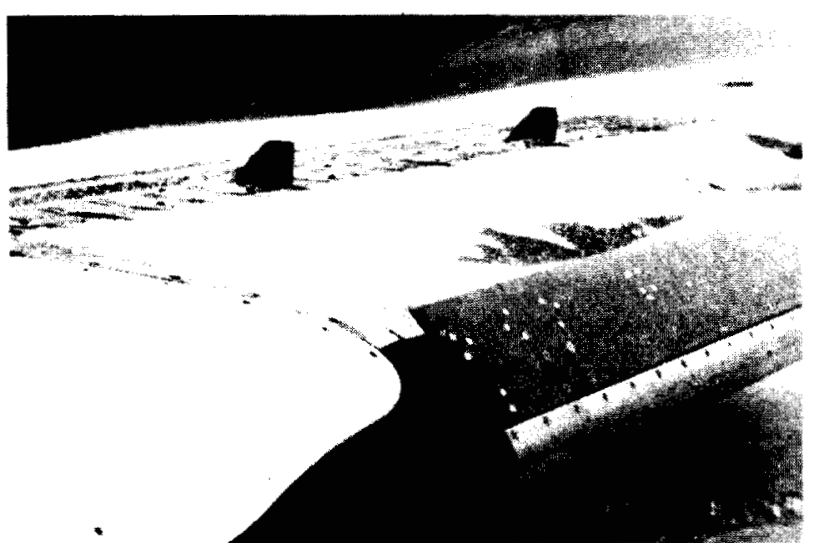

Figure 26 - Extended Krueger With Snow Deposits

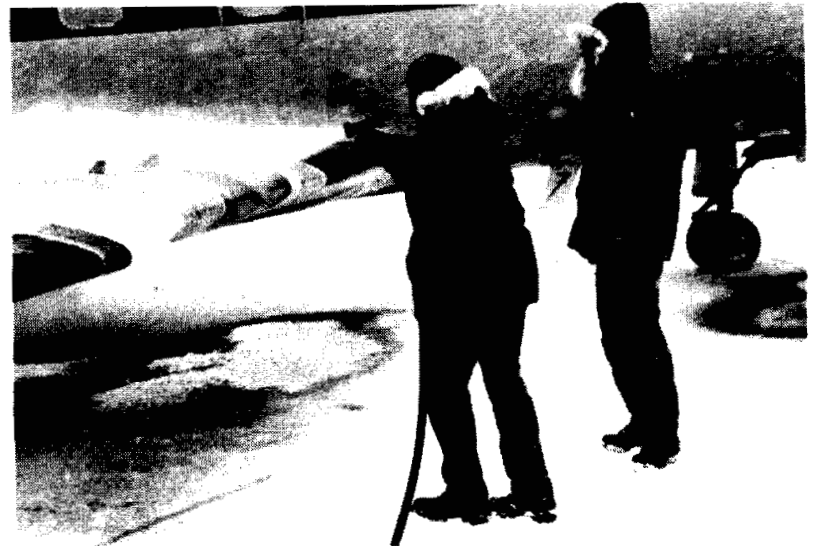

Figure 27 - Ground De-icing of Test Article

\section{Objective:}

Evaluate the effectiveness of HLFC for high speed subsonic transports

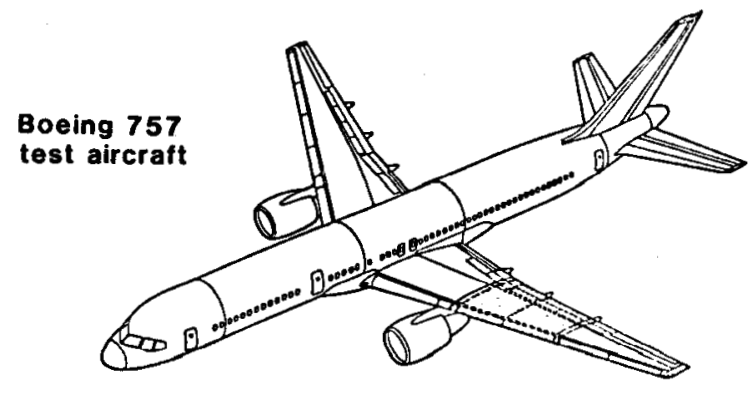

\section{- Joint NASA/USAF/Boeing Program}

Figure 28 - Boeing 757 Test Aircraft for High Reynolds Number HLFC Flight Experiment

Technical Features: - Cruise Conditions

$-M_{\infty}=0.8$
$-R_{C}=30 \times 10^{\circ}$

- Alt. $=34 \mathrm{~K}$ to $42 \mathrm{~K} \mathrm{ft}$.

- Laminar Flow, 38 to $62 \%$ chord

- Suction to Front Spar

- Microperforated Titanium Suction Surface

- All Metal Construction

- Operational Systems

- Leading Edge Krueger/Insect

Shield

- Anti-icing

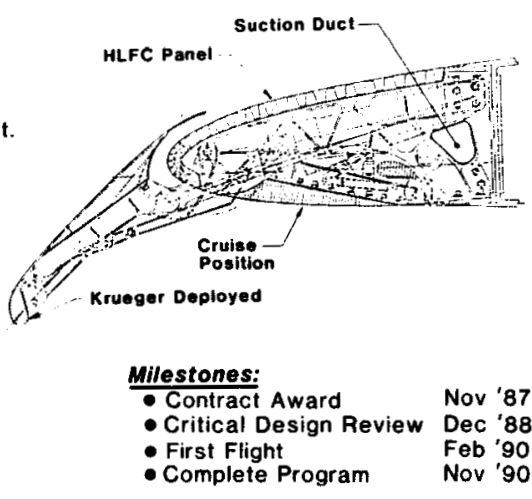

Figure 29 - Cross Section of Modified 757 Leading Edge 